\title{
Process Parameters Optimization of an Aluminium Alloy with Pulsed Gas Tungsten Arc Welding (GTAW) Using Gas Mixtures
}

\author{
Pawan Kumar ${ }^{1}$, Kishor Purushottamrao Kolhe ${ }^{2}$, Sashikant Janardan Morey ${ }^{3}$, \\ Chanchal Kumar Datta ${ }^{1}$
}

\begin{abstract}
${ }^{1}$ Department of Mechanical Engineering, Delhi College of Engineering, Delhi, India; ${ }^{2}$ Department of Mechanical Engineering, Agricultural University, Ratnagiri, India; ${ }^{3}$ Department of Production Engineering, College of Engineering and Technology, Akola, India. Email: \{kishor_kolhe, ckd5929\}@rediffmail.com,pks_munesh@yahoo.com
\end{abstract}

Received December $7^{\text {th }}, 2010$; revised February $1^{\text {st }}, 2011$; accepted March $4^{\text {th }}, 2011$.

\begin{abstract}
This paper demonstrates the enhancement of mechanical properties and effective optimization of pulsed GTAW process parameters on aluminium alloy 6061 using sinusoidal AC wave with argon plus helium gas mixtures. Modified Taguchi Method (MTM) was employed to formulate experimental layout and to study effect of process parameter optimization on mechanical properties of the weld joints. Microstructural characterization of weld joint was carried out to understand the structural property correlation with process parameters.
\end{abstract}

Keywords: Pulsed GTAW, Aluminium Alloy 6061, Gas Mixtures, Mechanical Properties, Modified Taguchi Method, Microstructures

\section{Introduction}

Aluminium alloy 6061 (Al-Mg-Si alloy) is widely used in the fabrication of food processing equipment, chemical containers, passenger cars, road tankers and railway transport systems due to its high strength, excellent weldability and resistance to corrosion. As these Al alloys (6xxx series) are precipitation-hardened, they suffer from a strength reduction in heat affected zone (HAZ) and like most face-centered cubic metals, they do not exhibit clear endurance limit [1]. GTAW is an arc welding process, where arc is produced between non-consumable tungsten electrode and base metal. Pulsed GTA welding process is frequently used for welding of aluminium alloys as heat input during welding can be precisely controlled. This process is strongly characterized by bead geometry, which plays an important role in determining mechanical properties of the weld [2]. Pulse process variables are controlling factor for heat input, which in turn leads to grain refinement in fusion zone, width reduction of HAZ, segregation of alloying elements, reducing hot cracking sensitivity and residual stresses $[3,4]$.

Improved mechanical properties of weld are achieved by using current pulsing due to the grain refinement oc- curring in the fusion zone. The main aim of pulsing is to achieve maximum penetration without excessive heat built-up. The use of high current pulses is to penetrate deep and cater for longer arc period at lower current. Deep penetration in pulsed current welding is produced by arc pressure at peak for longer durations [4]. In addition to this argon-helium gas mixture offers certain advantages by increasing heat input of the arc during welding. Argon is known for stable arc with better arc ignition whereas helium provides higher thermal conductivity. There exists a linear relationship between heat input of a weld and maximum temperature at a given distance from the weld centre line. It shows that pulsed arc welds are cooler and exhibit less thermal distortion than conventional GTA welds of the same penetration [5]. Heat input is typically calculated as follows:

$$
H=[60 E I] / 1000 S
$$

where $H=$ Heat Input $(\mathrm{kJ} / \mathrm{mm}), E=$ Arc Voltage (Volts), $I=$ Current (Amps) and $S=$ Travel Speed $(\mathrm{mm} / \mathrm{min})$.

The evolution of microstructure in weld fusion zone is influenced by current pulsing and cyclic variations of energy input into the weld pool causing thermal fluctuations. Consequently this leads to periodic interruption in solidification process. As pulse current decays, solid liq- 
uid interface advances towards the arc and becomes susceptible for disturbances in the arc formation. As current increases again in the subsequent pulse, the growth of dendrites can also occur. Current pulsing also results in periodic variations of the arc forces resulting in additional fluid flow, which lowers the temperature in front of the solidifying interface. Furthermore, the temperature fluctuations inherent in pulsed welding leads to a continual change in the weld pool size and shape favoring growth of new grains. It is to be understood that effective heat input for unit volume of weld pool should be considerably less in pulse current welds and thus expecting the average weld pool temperatures to be low [6].

A weldment basically consists of five microstructurally distinct regions normally identified as fusion zone, unmixed region, partially melted region, HAZ, and unaffected base metal. The HAZ is the portion of weld joint which experiences peak temperatures high enough to produce solid-state microstructural changes but they are too low to cause any melting. Every point of the weldment in the HAZ relative to the fusion line is subjected to unique thermal experience during welding, in terms of both maximum temperature and cooling rate. Thus, each point has its own microstructural features and corrosion susceptibility. Partially melted region extends usually one or two grains into the HAZ relative to the fusion line. It is characterized by grain boundary liquation, which may result in liquation cracking. An increase in the pulse frequency refines grain structure of weld metal using pulses of short duration. At a given frequency, long pulse duration produces coarser grain structure than shorter pulse duration. Further increase in the peak current leads to coarseness of grain structure [7].

Taguchi method is a powerful tool for design of high-quality systems, widely used for improving quality without increasing cost and with minimum experimentation. It provides a simple, efficient and systematic approach to optimize designs for performance, quality and cost. This method is valuable when process parameters are qualitative and discrete. The parameter design based on the Taguchi method can optimize the quality characteristics through the settings of process parameters and reduce the sensitivity of the system performance to the sources of variation [8]. In fact, Taguchi method had been designed to optimize a single quality characteristic. However, Modified Taguchi method (MTM) is used for several quality characteristics taken together into consideration for selection of process parameters $[9,10]$.

\section{Experimental Procedure}

The material under investigation is $5.00 \mathrm{~mm}$ thick $\mathrm{Al}$ alloy 6061. A non-consumable tungsten electrode of 2.4 mm $\Phi$ shielded by argon gas is used to strike the arc with base metal. Filler rods (31.5 $\mathrm{mm} \Phi)$ of Aluminium alloy 5183 are recommend for welding of this alloy for getting maximum strength and elongation. The chemical composition of base metal and filler rod are tabulated in Table 1. Sample plates of size $300 \times 150 \times 5 \mathrm{~mm}$ were prepared by milling and EDM wire-cut machines. Welding of the samples was carried out on Automatic Pulse GTAW Triton $220 \mathrm{~V} \mathrm{AC/DC}$. In order to remove oil, moisture and oxide layer from base metal, they were thoroughly wire brushed, cleaned with acetone and preheated at $150^{\circ} \mathrm{C}$ in the oven. The quality of weld is based on the process parameters, such as pulse current in the range of 150 $210 \mathrm{~A}$, base current in the range of $75-135 \mathrm{~A}$, pulse frequency in the range of $50-150 \mathrm{~Hz}$, pulse-on-time in the range of $30 \%-90 \%$ and percentage of $\mathrm{He}$ in $\mathrm{Ar}+\mathrm{He}$ mixtures in a range of $10 \%-50 \%$.

Tensile specimens of required dimension as per ASTM E8M were separated out from welded coupon plates and tests were carried out on $400 \mathrm{kN}$ computer controlled Universal Testing Machine. The specimens were loaded at the rate of $1.5 \mathrm{kN} /$ minute as per ASTM specifications, so that the tensile specimen undergoes deformation. All specimens finally fail after necking and the influence of load on displacement profile was recorded. Higher the tensile properties have better quality characteristics.

At the same time for microhardness measurement, samples of transverse cross-section of joint were taken from the weld coupons. The specimens formicrostructural characterization were mechanically polished using 220, 320, 400, 600 and 1000 grit waterproof SiC emery papers and alumina grade-II paste. Microhardness tests were carried out on a Leco Digital Microhardness Tester with $50 \mathrm{gf}$ load and 15 second dwell time incorporated with diamond indenter. Final polishing was carried out using 3 and $1 \mu \mathrm{m}$ diamond paste. To reveal the macrostructures of the welded sample, deep etching technique using $10 \% \mathrm{HF}$ acid solution in water was used. However, for further revealing of microstructures, Keller's reagent was used as etchants. Metallurgical microscope coupled with Image Analysis system was used for the microstructural characterization and to measure the porosity level in the weldment.

Table 1. Chemical composition of Base metal and filler rod.

\begin{tabular}{ccccccc}
\hline \multirow{2}{*}{$\begin{array}{c}\text { Aluminium } \\
\text { Alloys }\end{array}$} & $\mathrm{Mg}$ & $\mathrm{Si}$ & $\mathrm{Cu}$ & $\mathrm{Zn}$ & $\mathrm{Mn}$ & $\mathrm{Al}$ \\
\cline { 2 - 7 } & 1.1 & 0.7 & 0.25 & 0.25 & - & Rest \\
6061 & 4.55 & - & - & 0.1 & 0.65 & Rest \\
\hline
\end{tabular}




\section{Selection of Process Parameters and Their Limits}

The bead profile and quality of the GTA weld is greatly dependent on the joint design, welding position and proper selection of process parameters, such as current polarity, pulse current, secondary current (base current), pulse frequency, pulse duty cycle, welding voltage, welding speed, arc length and shielding gas flow rate. The thermal behaviour of weld is governed by arc characteristics. The metal transfer during welding significantly affects the weld bead geometry, chemistry and microstructure [11]. Welding parameters are selected on the basis of literature survey.

A large number of trial runs were carried on $5 \mathrm{~mm}$-thick aluminium alloy 6061 samples to find out the feasible working limits of pulsed current GTAW parameters. After examining bead morphology of samples, the upper and lower limit of the peak current, base current, pulse duty cycle and pulse frequency were decided. The process parameters and their levels are shown in Table 2. Some constant process parameters used during welding are shown in Table 3 . The bead contour, bead appearance and weld quality of the weld joint were inspected in order to identify the welding parameters. From the above analysis, following observations are made:

1) If the peak current $(\mathrm{P})$ was less than $150 \mathrm{~A}$, incomplete penetration and lack of fusion were observed. At the same time, if $\mathrm{P}$ exceeds $210 \mathrm{~A}$, the defects like under cut, spatters and overheating were observed.

2) If base current (B) was lower than $75 \mathrm{~A}$, heat input was very less because of very short arc length. On the other hand, for B greater than $135 \mathrm{~A}$, arc became unstable and lengthy.

3) If the pulse frequency (F) was lower than $50 \mathrm{~Hz}$, the bead contour and bead appearance was not of good quality. However, if the F was larger than $150 \mathrm{~Hz}$, the harsh sound emanated from welding machine.

4) If the pulse duty cycle (T) was less than $30 \%$, the generated heat input was not sufficient to melt the base metal. On the contrary, if $\mathrm{T}$ was larger than $90 \%$, over melting of base \& filler metals and overheating of tungsten electrode were observed.

5) If the helium (X) in mixture of argon and helium was less than $10 \%$, the arc stability, bead penetration and bead appearance were poor. On the other hand if X was greater than $50 \%$, gas consumption gas mixture per $\mathrm{kg}$ weld deposition was very high.

\section{Optimum Selection of Process Parameters by MTM}

Modified Taguchi Method (MTM) is used to find out the optimal process parameters to enhance the mechanical
Table 2. Process Parameters and their limiting Values.

\begin{tabular}{clcccccc}
\hline \multirow{2}{*}{ Symbol } & Process & \multirow{2}{*}{ Unit } & \multicolumn{7}{c}{ Levels } \\
& Parameter & & 1 & 2 & 3 & 4 & 5 \\
\hline P & Peak Current & A & 150 & 165 & 180 & 195 & 210 \\
B & Base Current & A & 75 & 90 & 105 & 120 & 135 \\
F & Pulse Frequency & $\mathrm{Hz}$ & 50 & 75 & 100 & 125 & 150 \\
T & Pulse Duty & $\%$ & 30 & 45 & 60 & 75 & 90 \\
& Cycle & & & & & & \\
X & Percentage of & $\%$ & 10 & 20 & 30 & 40 & 50 \\
\hline
\end{tabular}

Table 3. Constant Process Parameters.

\begin{tabular}{lc}
\hline Process Parameters & Constant Values \\
\hline Shielding gas (Argon) flow rate, 1/min & 8.0 \\
Filler rod diameter, mm & 3.15 \\
Electrode material & $98 \% \mathrm{~W}+2 \% \mathrm{Zr}$ \\
Electrode diameter, mm & 2.4 \\
AC Balance, \%age & 0.00 (Sinusoidal) \\
\hline
\end{tabular}

properties by conducting minimum experimental runs.

\subsection{Orthogonal Array}

In this study, four levels were chosen for four factors. Limiting values of these factors are tabulated in Table 2. There are 20 degrees of freedom and hence L25 orthogonal array was used. Experimental layout for conducting test is shown in Table 4.

Table 4. Experimental Layout using L25 Orthogonal Array.

\begin{tabular}{|c|c|c|c|c|c|}
\hline \multirow{2}{*}{ Expt No. } & \multicolumn{5}{|c|}{ Levels of Process Parameters } \\
\hline & $\mathrm{P}$ & $\mathrm{B}$ & $\mathrm{F}$ & $\mathrm{T}$ & $\mathrm{X}$ \\
\hline 1 & 1 & 1 & 1 & 1 & 1 \\
\hline 2 & 1 & 2 & 2 & 2 & 2 \\
\hline 3 & 1 & 3 & 3 & 3 & 3 \\
\hline 4 & 1 & 4 & 4 & 4 & 4 \\
\hline 5 & 1 & 5 & 5 & 5 & 5 \\
\hline 6 & 2 & 1 & 2 & 3 & 4 \\
\hline 7 & 2 & 2 & 3 & 4 & 5 \\
\hline 8 & 2 & 3 & 4 & 5 & 1 \\
\hline 9 & 2 & 4 & 5 & 1 & 2 \\
\hline 10 & 2 & 5 & 1 & 2 & 3 \\
\hline 11 & 3 & 1 & 3 & 5 & 2 \\
\hline 12 & 3 & 2 & 4 & 1 & 3 \\
\hline 13 & 3 & 3 & 5 & 2 & 4 \\
\hline 14 & 3 & 4 & 1 & 3 & 5 \\
\hline 15 & 3 & 5 & 2 & 4 & 1 \\
\hline 16 & 4 & 1 & 4 & 2 & 5 \\
\hline 17 & 4 & 2 & 5 & 3 & 1 \\
\hline 18 & 4 & 3 & 1 & 4 & 2 \\
\hline 19 & 4 & 4 & 2 & 5 & 3 \\
\hline 20 & 4 & 5 & 3 & 1 & 4 \\
\hline 21 & 5 & 1 & 5 & 4 & 3 \\
\hline 22 & 5 & 2 & 1 & 5 & 4 \\
\hline 23 & 5 & 3 & 2 & 1 & 5 \\
\hline 24 & 5 & 4 & 3 & 2 & 1 \\
\hline 25 & 5 & 5 & 4 & 3 & 2 \\
\hline
\end{tabular}




\subsection{Experimental Results}

The experiments were conducted as per orthogonal array and results of the mechanical properties as ultimate tensile strength (UTS), microhardness of weld zone and percentage elongation are tabulated in Table 5. All tensile specimens fractured at weld joint, therefore their mechanical properties correspond to that of weld joint. Also microhardness profile of three samples $(03,08$ and 11) were measured at a distance of $0.5 \mathrm{~mm}$ across the weld as shown in Figure 1 and plotted in Figure 2.

Microstructures of above three samples were characterized by image analysis system for the measurement of porosity level and grain size of the weld zone and HAZ. It was observed that the grain size of the sample 11 was less then 08 and 03 samples in both the HAZ and weld area. Also the porosity level in the weld joint of D11 was comparatively lower than that of the 08 and 03 samples. Microstructures and characterization data of 11,08 and 03 samples (weld zone and HAZ) are shown in Figure 3 and Table 6 respectively.

For optimizing the process parameters, four quality characteristics were considered for a single characteristic. Hence the Modified Taguchi Method (MTM) is used. Weighted response of mechanical properties was obtained by adding weights to the responses as a single quality

Table 5. Experimental results for the mechanical properties.

\begin{tabular}{|c|c|c|c|}
\hline $\begin{array}{l}\text { S. } \\
\text { No. }\end{array}$ & UTS (MPa) & $\begin{array}{c}\text { Microhardness } \\
\text { (VPN) }\end{array}$ & Elongation (\%age) \\
\hline 01. & 256.40 & 114.1 & 08.71 \\
\hline 02. & 267.47 & 112.6 & 12.94 \\
\hline 03. & 283.36 & 098.7 & 10.00 \\
\hline 04. & 288.08 & 112.5 & 10.90 \\
\hline 05. & 298.75 & 112.9 & 09.70 \\
\hline 06. & 293.76 & 105.8 & 07.84 \\
\hline 07. & 290.74 & 097.8 & 09.00 \\
\hline 08. & 352.85 & 110.6 & 09.08 \\
\hline 09. & 272.12 & 120.8 & 09.92 \\
\hline 10. & 386.07 & 099.2 & 10.70 \\
\hline 11. & 290.74 & 109.0 & 10.00 \\
\hline 12. & 272.63 & 112.4 & 10.36 \\
\hline 13. & 282.62 & 109.3 & 12.06 \\
\hline 14. & 280.75 & 100.5 & 10.86 \\
\hline 15. & 300.95 & 103.9 & 08.12 \\
\hline 16. & 300.18 & 105.7 & 09.20 \\
\hline 17. & 288.05 & 107.0 & 11.30 \\
\hline 18. & 282.42 & 102.2 & 09.32 \\
\hline 19. & 290.74 & 115.4 & 10.58 \\
\hline 20. & 278.27 & 101.4 & 09.90 \\
\hline 21. & 295.69 & 108.1 & 10.60 \\
\hline 22. & 293.02 & 095.6 & 11.04 \\
\hline 23. & 294.00 & 102.5 & 09.62 \\
\hline 24. & 301.50 & 097.0 & 10.48 \\
\hline 25. & 310.03 & 099.5 & 10.58 \\
\hline
\end{tabular}

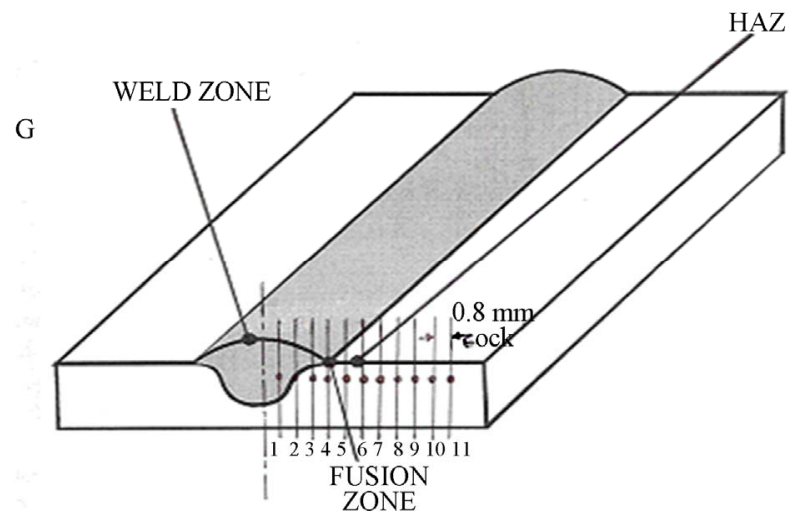

Figure 1. Macrograph of weld joint showing schematic of microhardness measurements .

Table 6. Microstructure characterization results of welded samples.

\begin{tabular}{cccc}
\hline $\begin{array}{c}\text { Sample } \\
\text { No. }\end{array}$ & $\begin{array}{c}\text { Grain Size in } \\
\mu \mathrm{m}(\mathrm{HAZ})\end{array}$ & $\begin{array}{c}\text { Grain Size in } \mu \mathrm{m} \\
\text { (Weld Zone) }\end{array}$ & $\begin{array}{c}\text { Porosity in } \\
\text { percentage }\end{array}$ \\
\hline 03 & $49 \pm 5$ & $17 \pm 3$ & 3 \\
08 & $37 \pm 5$ & $15 \pm 3$ & 2.5 \\
11 & $29 \pm 5$ & $12 \pm 3$ & 0.8 \\
\hline
\end{tabular}

characteristic. Also weights for UTS, microhardness inweld zone and elongation at break were selected as 0.640 , 0.254 and 0.106 respectively with help of AHP (Analytical Hierarchy Process). Weighted response is tabulated in Table 7.

\subsection{Analysis of Variance (ANOVA) Calculations}

Analysis of variance is most important tool for calculating responsible factors, which significantly affects mechanical properties. For determining these affect on process parameters, F-test was performed. Results of ANOVA and percentage contributions by each process parameters are tabulated in Table 8. Response graphs

Table 7. Weighted response for mechanical properties.

\begin{tabular}{cccc}
\hline Expt No. & Weighted Response & Expt No. & Weighted Response \\
\hline 1. & 185.78 & 14. & 196.99 \\
2. & 192.57 & 15. & 209.69 \\
3. & 197.97 & 16. & 209.84 \\
4. & 206.64 & 17. & 203.19 \\
5. & 210.99 & 18. & 198.26 \\
6. & 205.84 & 19. & 206.98 \\
7. & 202.02 & 20. & 195.63 \\
8. & 242.75 & 21. & 207.98 \\
9. & 197.18 & 22. & 203.06 \\
10. & 259.82 & 23. & 205.33 \\
11. & 205.17 & 24. & 208.45 \\
12. & 195.27 & 25. & 214.26 \\
13. & 200.65 & & \\
\hline
\end{tabular}




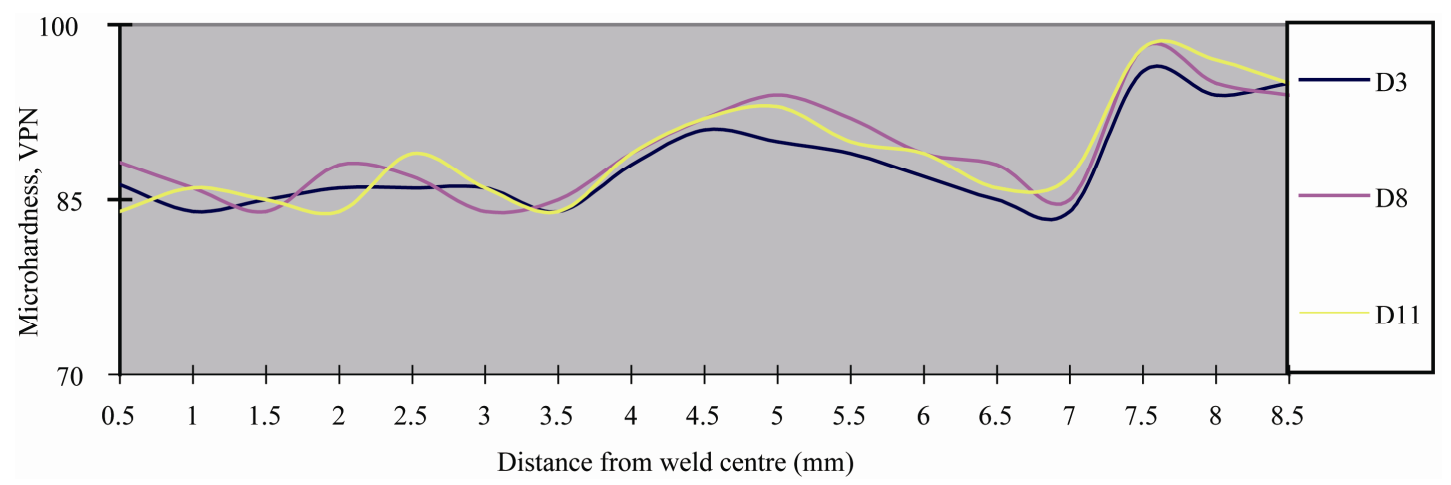

Figure 2. Microhardness Profile of GTA Welded Aluminum Alloy 6061.
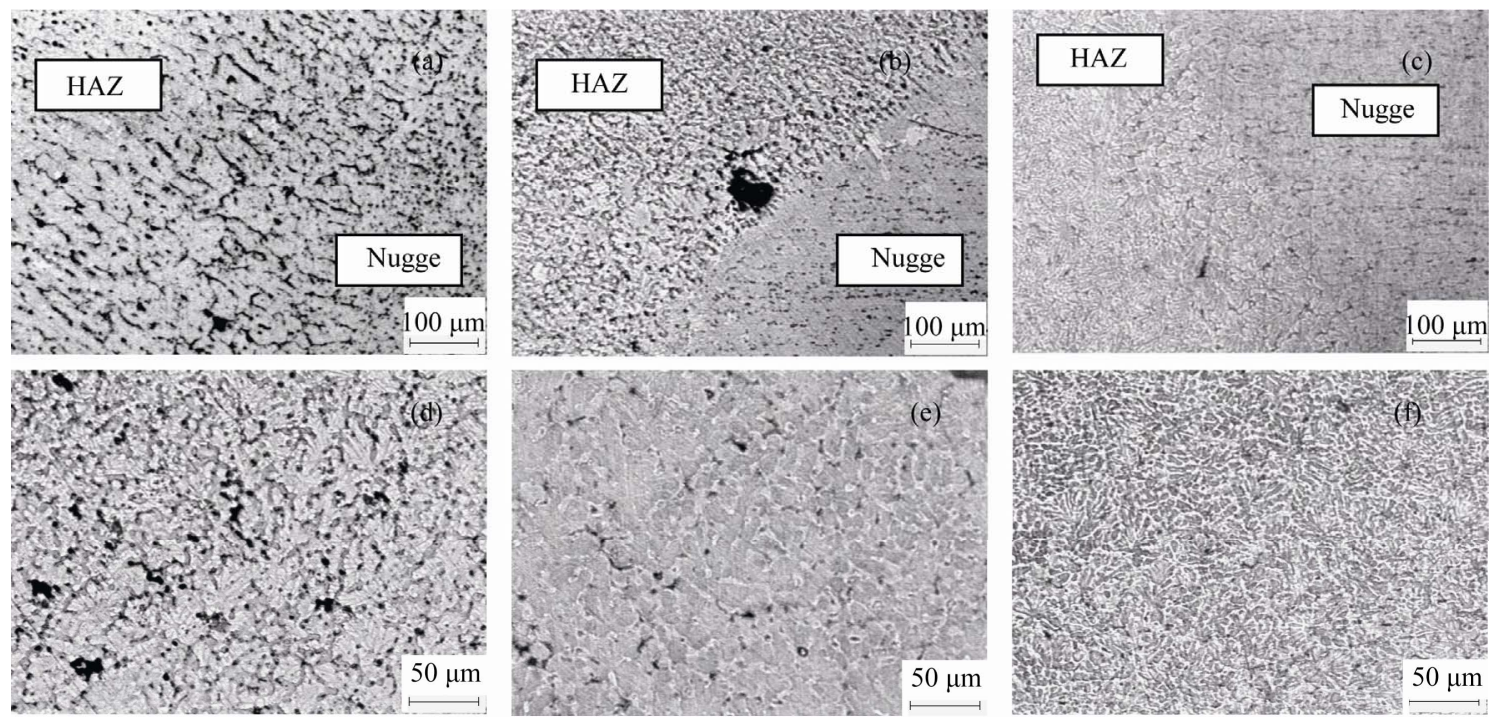

Figure 3. (a) 03, (b) 08, (c) 11, microstructures of HAZ and weld zone at 100X and (d) 03, (e) 08, (f) 11, microstructures of weld zone at 200X.

Table 8. Results of analysis of variance.

\begin{tabular}{lccccc}
\hline \multicolumn{1}{c}{ Welding parameter } & Deg of freedom & Sum of square & Mean square & F & Contributed \%age \\
\hline Pulse Current (A) & 4 & 1621.34 & 405.34 & 2.902 & 29.31 \\
Base Current (A) & 4 & 992.89 & 248.22 & 1.777 & 17.95 \\
Pulse Frequency (Hz) & 4 & 611.07 & 152.77 & 1.094 & 11.08 \\
Pulse Duty Cycle (\%) & 4 & 1205.99 & 301.49 & 2.158 & 21.80 \\
Percentage of He in Ar & 4 & 541.21 & 135.30 & 0.969 & 09.79 \\
Error & 4 & 558.79 & 139.69 & & 10.10 \\
Total & 24 & 5531.29 & & & \\
\hline
\end{tabular}

(Figure 4) are drawn from response table indicated Table 9 , to identify the significant levels of each factor.

\subsection{Confirmation Test}

Optimal level of process parameters was predicted using response graph and ANOVA. Process parameters and their levels which affect mechanical properties are pulse current at level 2, background current at level 5, pulse frequency at level 4, pulse duty cycle at level 2 and percentage of Helium in Argon at level 3. The obtained results were verified for the improvement in multiple quality characteristics by conducting a confirmation test based on results obtained in Table 10.

\section{Discussion}

ANOVA calculations shown in Table 8, shows that pulse 


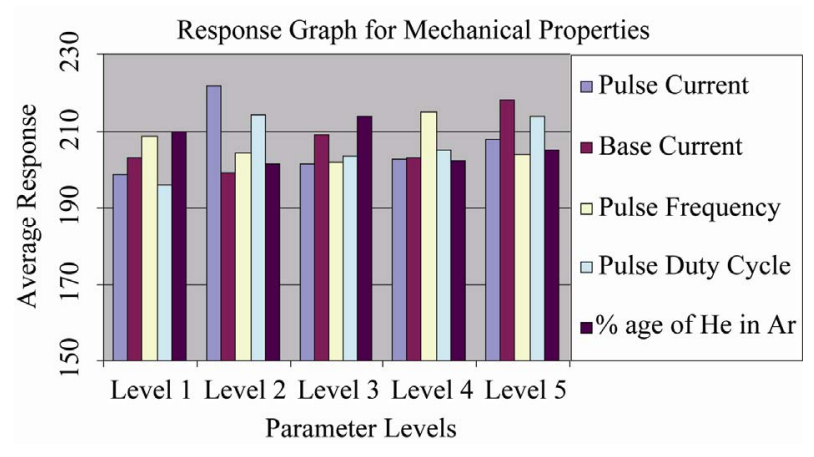

Figure 4. Response graph of mechanical properties.

current, base current, pulse duty cycle, frequency and percentage of Helium in Argon plays significant role on microstructure and mechanical properties of welded $\mathrm{Al}$ alloy 6061, but pulse current plays the maximum role i.e. $29.31 \%$. In this investigation, pulse current of $165 \mathrm{~A}$, background current of $135 \mathrm{~A}$, pulse frequency of $125 \mathrm{~Hz}$, pulse duty cycle of $45 \%$ and $30 \%$ of Helium with Argon affects the maximum to the mechanical properties.

As shown in Figure 2, all three samples show almost same trend of microhardness across weld zone, HAZ and base metal. Lower microhardness was observed in the weld zone in all samples because of using low hardness of filler rod, coarse dendritic solidified microstructure and interdendritic segregated phase. Microhardness of HAZ is also lower than base metal but at the fusion zone a higher value can be seen. This increase in microhardness is due to the fast cooling rate experienced near the weld area, which produces a super saturated solid solution. During subsequent cooling and natural ageing phenomena very fine precipitate of $\mathrm{Mg}_{2} \mathrm{Si}$ may have formed near weld area

Table 9. Response table for mechanical properties.

\begin{tabular}{cccccc}
\hline $\begin{array}{c}\text { Welding } \\
\text { parameter }\end{array}$ & Level 1 & Level 2 & Level 3 & Level 4 & Level 5 \\
\hline $\begin{array}{c}\text { Pulse } \\
\text { Current (A) } \\
\quad \text { Base }\end{array}$ & 198.79 & 221.52 & 201.54 & 202.78 & 207.82 \\
$\begin{array}{c}\text { Current (A) } \\
\text { Pulse }\end{array}$ & 202.92 & 199.22 & 208.99 & 203.25 & 218.08 \\
$\begin{array}{c}\text { Frequency (Hz) } \\
\text { Pulse Duty } \\
\text { Cycle (\%) }\end{array}$ & 208.78 & 204.08 & 201.85 & 214.87 & 203.99 \\
$\begin{array}{c}\text { Percentage } \\
\text { of He in Ar }\end{array}$ & 209.97 & 201.49 & 213.60 & 202.36 & 205.03 \\
\hline
\end{tabular}

Table 10. Confirmation test results.

\begin{tabular}{ccccc}
\hline Optimum & $\begin{array}{c}\text { Optimal level of } \\
\text { Response }\end{array}$ & $\begin{array}{c}\text { UTS } \\
\text { process parameters }\end{array}$ & $\begin{array}{c}\text { MPa } \\
\text { VPN }\end{array}$ & $\begin{array}{c}\text { Elongation } \\
\text { (Percentage) }\end{array}$ \\
\hline $\begin{array}{c}\text { Predicted } \\
\text { Experiment }\end{array}$ & P2 B5 F4 T2 X3 & 389.31 & 121.4 & 12.98 \\
\hline
\end{tabular}

of HAZ.

From microstructures as shown in Figure 3, it is apparent that sample 11 results in fine dendritic microstructure and lower porosity level as compared to other sample (03 and 08). Therefore from the microstructural characterization it is observed that the pulse parameters play an important role in development of fine microstructure.

\section{Conclusions}

An experimental study has been conducted to understand the effect of process parameters of pulsed current GTA welding on aluminium alloy weldments. Five important process parameters of pulsed current GTA welding were used with gas mixtures to optimize the four quality characteristics of mechanical properties. Modified Taguchi Method was used with success to identify the optimum parameters. Experimental results coupled with ANOVA results proved that pulse current is having pronounced effect on the multiple quality characteristics of the mechanical properties and microstructural characterization. Generation of fine dendritic microstructure resulted in improvement of mechanical properties. The confirmation experiments conducted with predicted levels of factors proved to be worthy.

\section{REFERENCES}

[1] T. Senthilkumar, V. Balasubramanian and M. Y. S. Babu, "Effect of Pulsed Current GTAW Parameters on Fusion Zone Microstructure of AA6061," International Journal of Metals \& Materials, Vol. 13, No. 4, 2007, pp. 345-351.

[2] S. C. Juang and Y. S. Tarng, "Process Parameter Selection for Optimizing the Weld Pool Geometry in the TIG Welding of Stainless Steel," Journal of Material Process Technology, Vol. 122, No. 1, 2002, pp. 33-37. doi:10.1016/S0924-0136(02)00021-3

[3] A. A. Mohamed, "Optimisation of Weld Bead Dimensions in GTAW of Al-Mg Alloy," Materials and Manufacturing Processes, Vol. 16, No. 5, 2001, pp. 725-736.

[4] M. Balasubramanian, V. Jayabalan and V. Balasubramanian, "Optimizing the Pulsed Current GTAW Parameters to Attain Maximum Impact Toughness," Materials and Manufacturing Processes, Vol. 23, No. 1-2, 2008, pp. 69-73. doi:10.1080/10426910701524584

[5] R. E. Leitner, H. Mcelhinney and E. I. Pruitt, "Aninvestigation of Pulsed Welding Variables," Welding Journal, Vol. 52, No. 9, 1973, pp. 405-410.

[6] G. M. Reddy, A. A. Gokhale and K. P. Rao, "Optimization of Pulse Frequency in Pulsed Current Gas Tungsten Arc Welding of Aluminium-Lithium Alloy Sheets," Journal of Material Science and Technology, Vol. 14, 1998, pp. 61-66.

[7] R. Manti, D. K. Dwivedi and A. Agarwal, "Microstruc- 
ture and Hardness of Al-Mg-Si Weldments Produced by Pulse GTA Welding," International Journal of Advance Manufacturing Technology, Vol. 36, No. 3-4, 2008, pp. 263-269. doi:10.1007/s00170-006-0849-Z

[8] Y. S. Tarng and W. H. Yang, "Optimization of the Weld Bead Geometry in GTA Welding by the Taguchi Method," International journal of Advance Manufacturing Technology, Vol. 14, 1998, pp. 549-554.

[9] A. Kumar and S. Sundarrajan, "Optimization of Pulsed TIG Welding Process Parameters on Mechanical Properties of AA 5456 Al Alloy Weldments," Materials and
Design, Vol. 30, No. 4, 2009, pp. 1288-1297. doi:10.1016/j.matdes.2008.06.055

[10] A. Kumar and S. Sundarrajan, "Selection of Welding Process Parameters for the Optimum but Joint Strength of an Aluminum Alloy," Material and Manufacturing Process, Vol. 21, No. 8, 2006, pp. 789-793.

[11] M. Balasubramanian and V. Balasubramanain, "Process Parameter Optimisation of the Pulsed GTAW of Titanium Alloy," Journal of Material Science and Technology, Vol. 24, No. 3, 2008, pp. 423-426. 